\title{
Clinical decision-making and patients expectations: is there a link?
}

\author{
R. Gunzburg
}

Received: 9 January 2015/Revised: 9 January 2015 / Accepted: 9 January 2015/Published online: 22 January 2015

(C) Springer-Verlag Berlin Heidelberg 2015

The European Spine Journal constitutes a forum where all aspects related to the spine are discussed. This includes cognitive aspects and their relationship to the spine.

In the course of treating a condition both doctors and patients have expectations and ideally these should align. In this issue, we see how Kamper et al. [1] examined whether expectations change over time, but there are many other factors influencing patient's expectations. The quality of the patient-doctor relationship, the cultural background and illness perception are but a few. There is place for more scrutiny.

Psychological studies have long shown the effects of expectations on judgment. Patients and doctors continuously face the challenge of clinical decision-making, and here too, there are many factors influencing this process. Is there a link? Does a clinical decision-making affect patient's expectations or vice versa? In other words, can a patient have different expectations for option A and option B? The European Spine Journal has a particular interest in these questions and looks forward to further research in the field.

Conflict of interest None.

\section{Reference}

1. Kamper SJ, Kongsted A, Haanstra TM, Hestbaek L (2015) Do recovery expectations change over time? Eur Spine J. doi:10.1007/ s00586-014-3380-1

R. Gunzburg $(\bowtie)$

Edith Cavell Clinic, Cavell Spine Centre, Edith Cavell Street 32,

1180 Brussels, Belgium

e-mail: robert@gunzburg.be 